\title{
AS ORGANIZAÇÕES COMO FONTE DE CONFLITOS DE PODER
} ORGANIZATIONS AS POWER CONFLICT SOURCES

\author{
Data de submissão: 22-07-2013 \\ Aceite: 14-12-2014 \\ Raul Dalla Lana ${ }^{1}$ \\ Patrícia Andrade Paines ${ }^{2}$ \\ Saul Azzolin Bonaldo 3 \\ Felipe Martins Müller ${ }^{4}$
}

\section{RESUMO}

Abordam-se, no presente artigo, algumas formas organizacionais com base no poder; os conflitos, poder e conflito, exercício do poder nas organizações e a resolução de conflitos. Utilizou-se a pesquisa bibliográfica como metodologia de trabalho, uma vez que, a mesma propicia a releitura de um tema, sob um novo enfoque, dos escritos de autores como Bowditch, Galbraith, Mintzberg, Moscovici, Spector, entre outros. A literatura aponta que os conflitos podem ser considerados tanto benéficos, como maléfico à organização, uma vez que podem motivar o funcionário a um crescimento, tanto pessoal, quanto profissional, colaborando, dessa forma, para uma melhoria do desempenho individual e do grupo. Para a resolução desses conflitos, a negociação é uma alternativa indicada, desde que o profissional designado para tal seja capacitado, isto é, que tenha conhecimento do processo desencadeador do conflito para, dessa forma, buscar uma solução que satisfaça de maneira razoável e justa aos objetivos, interesses, necessidades e aspirações das partes envolvidas no conflito. Assim, os conflitos ao mesmo tempo em que representam uma ameaça à estabilidade de uma organização, podem também representar uma via de crescimento conjunto, para que a organização, o gestor e o colaborador possam sair fortalecidos de uma situação conflitante, desde que usadas alternativas corretas para a solução do mesmo.

Palavras-chave: Organização, Poder, Conflito, Gestão de Pessoas.

\footnotetext{
1 Possui licenciatura pela em Estudos Sociais pela Faculdade de Filosofia, Ciências e Letras “Imaculada Conceição", Pós-graduação em Gestão de Recursos Humanos pela Faculdade de Tecnologia Internacional - FATEC INTERNACIONAL. Santa Maria. Rio Grande do Sul. Brasil. E-mail: rauldallalana@gmail.com

2 Possui graduação em Matemática pela Universidade Federal de Santa Maria, UFSM, Mestrado em Engenharia de Produção pela Universidade Federal de Santa Maria, UFSM e Doutorado em andamento em Engenharia de Produção.

Universidade Federal de Santa Catarina, UFSC. Florianópolis. Santa Catarina. Brasil. E-mail: paines_sm@hotmail.com

3 Possui Graduação em Engenharia Elétrica pela Universidade Federal de Santa Maria, UFSM, Mestrado em Engenharia Elétrica pela Universidade Federal de Santa Maria, UFSM e Doutorado em Engenharia Agrícola pela Universidade Federal de Santa Maria, UFSM. Santa Maria. Rio Grande do Sul. Brasil. E-mail: saul@bonaldo.eng.br

4 Possui Graduação em Engenharia Elétrica pela Universidade Federal de Santa Maria, UFSM, Mestrado em Engenharia Elétrica pela Universidade Estadual de Campinas, UNICAMP e Doutorado em Engenharia Elétrica pela Universidade Estadual de Campinas, UNICAMP. Santa Maria. Rio Grande do Sul. Brasil. E-mail: felipe@inf.ufsm.br
} 


\begin{abstract}
In this paper are presented a few power based organizations; the conflicts, power and conflict, power excercise and conflict resolution. Bibliographic research was used as this paper methodology, as it enables a rereading about the topic with a new perspective on writings from Bowditch, Foulcault, Galbraith, Mintzberg, Moscovici, Spector, and others. Literature points that the conflicts can be considered beneficial or malefic to the organization, as they can motivate an employee to grow, personally and professionally, possibilitating an better individual and group perforamnce. As to the resolution of this conflicts, the negotiation is an indicated alternative, as long as the professional in charge is capacitated, that is, he has the knowledge of the conflict generating process, to search for a solution that meets, in a reasonable and just way, the objectives, interests, needs and aspirations of the parts involved in the conflict. Therefore, the conflict can impose a threat to the organization stability as it can allow mutual growth, that is, the company, administrator and colaborator can get benefitted from a conflicting situation, as long as the correct alternatives are used for the conflict solving.
\end{abstract}

keywords: organization, power, conflict, people managment

\title{
1 INTRODUÇÃO
}

A ausência de conflitos, até pouco tempo, era vista como garantia de bom ambiente, de boas relações e, no caso das organizações, era sinal de competência, pois grande parte dos gestores percebia o conflito como algo negativo, resultado de uma ação ou mau comportamento de algumas pessoas. Associavam a agressividade ao confronto físico e verbal e também aos sentimentos ruins, considerados prejudiciais ao bom relacionamento entre as pessoas e ao bom funcionamento das organizações. No entanto, com a chegada da sociedade contemporânea, o conflito passou a ser entendido de outras formas, bem como a solução do mesmo passou a ter outras abordagens.

Essas novas abordagens, envolvendo conflitos de poder nas organizações, foram a fonte motivadora para a realização deste trabalho. Assim, abordam-se algumas formas organizacionais com base no poder, como: os conflitos, poder e conflito, exercício do poder nas organizações e a resolução de conflitos.

Utilizou-se a pesquisa bibliográfica como metodologia de trabalho, uma vez que, a mesma propicia uma releitura de um tema sob um novo enfoque, permitindo conclusões inovadoras. Para tanto, utilizou-se escritos de autores como Bowditch, Foulcault, Galbraith, Mintzberg, Moscovici, Spector, entre outros.

Por fim, apresentam-se algumas considerações finais sobre o tema.

\section{METODOLOGIA}

A elaboração do presente artigo foi norteada pela pesquisa bibliográfica, a qual no entendimento de Lakatos e Marconi (2003, p. 183), tem por objetivo conhecer as diferentes contribuições científicas disponíveis sobre determinado tema, dando suporte a todas as fases de qualquer tipo de pesquisa, auxiliando na definição do problema, na determinação dos objetivos, na construção de hipóteses, na fundamentação da justificativa da escolha do tema e na elaboração do relatório final.

No mesmo sentido, Manzo (1971, p. 32) citado por Lakatos e Marconi (2003, p. 183) afirma que a pesquisa da bibliografia pertinente oferece meios para definir e resolver, não somente problemas já conhecidos, como também explorar novas áreas em que os problemas ainda não se cristalizaram suficientemente, permitindo ao cientista o reforço paralelo à análise de suas pesquisas ou manipulações de suas informações. 
Nessa perspectiva, a pesquisa bibliográfica não é mera repetição do que já foi dito ou escrito sobre determinado assunto, mas propicia o exame de um tema sob novo enfoque ou abordagem, permitindo conclusões inovadoras.

\section{AS ORGANIZAÇÕES E O PODER}

O poder é definido por Galbraith (1989) como a capacidade de impor a vontade e atingir um objetivo. Foucault (1993) acrescenta que o poder é algo que se exerce em rede. No mesmo sentido, Fischer (1989) ressalta que o poder está embutido nos padrões culturais vigentes, estando presente em todas as esferas da organização, atingindo diferentes agentes organizacionais, sendo por eles manipulado nas disputas de interesses e influências.

De acordo com Bowditch (1992, p. 36), "poder é a capacidade de influenciar diversos resultados". Cita o poder da posição como o mais comum entre os líderes nomeados, sendo o mesmo impessoal, não estando alicerçado em características individuais. Alerta esse autor, que líderes nomeados podem utilizar os sistemas de recompensas formais da organização ou até mesmo punições para influenciar as pessoas a fazerem determinadas atividades, sendo essas denominadas de poder de recompensa e de coerção.

No entendimento de Macêdo (2002, p. 5), nas relações de poder há um desequilíbrio de forças entre duas partes com interesses divergentes, onde uma impõe sua vontade sobre a outra e faz com que esta faça coisas que de outra forma não faria.

Conforme Bertero (In: FLEURY; FISCHER, 1996, p. 29), o poder na organização empresarial trilha um itinerário: "num primeiro momento o poder encontra-se centrado na figura do proprietário". Este estágio corresponde, nos países capitalistas clássicos, ou do primeiro mundo, à fase inicial do capitalismo industrial. À medida que é visto como único responsável pelo empreendimento, a ele cabe às decisões em sua quase totalidade. Em tal estágio, a firma é pequena e, conseqüentemente, a necessidade de descentralização administrativa ainda não se instalou o que implica a ausência de um segmento de profissionais de administração. Este é o estágio em que o poder centrado no proprietário corresponde historicamente a um período em que as pressões e constrangimentos externos sobre a empresa eram reduzidos. Apesar da pressão dos sindicatos de empregados.

Num segundo momento, o poder organizacional começa a se difundir. Os primeiros influenciadores do poder passam a serem membros do que se pode chamar de coalização interna, ou seja, profissionais de administração, gestores que não são proprietários. O núcleo dos influenciadores internos se forma devido à expansão da empresa. Portanto, a variável explicativa é o tamanho dos negócios e a necessidade de especialistas que dominem habilidades administrativas ou conhecimentos tecnológicos. A fase da difusão do poder a partir do proprietário para os influenciadores internos é frequentemente chamada, na história dos negócios, de profissionalização administrativa ou formação dos quadros (BERTERO in: FLEURY; FISCHER, 1996, p. 30).

No entanto, Bertero (In: FLEURY; FISCHER, 1996, p. 31) alerta que essa segunda fase também comporta outra dimensão: o aparecimento dos influenciadores externos, que se fazem presentes à medida que a empresa deixa de ser vista pela sociedade como organização que interessa exclusivamente ao seu proprietário e aqueles que nela trabalham como associados, para ser percebida como atingindo, pela sua operação, à comunidade. A emergência dos influenciadores externos se faz à medida que o sistema capitalista se desenvolveu com o conseqüente aumento de visibilidade da importância das organizações empresariais. Assim, o poder nos diversos sistemas e subsistemas sociais tem suas fontes em diversos agentes, que, por sua vez, estabelecem entre si relações múltiplas. Para Bertero (in: FLEURY; FISCHER, 1996, p. 31), os influenciadores externos incluem: 
o governo, entendido em seus diversos níveis, federal, estadual e municipal, bem como governos de países estrangeiros e organizações internacionais caso a empresa se multinacionalize, ou simplesmente venha a efetuar transações com outros países. Além do governo, incluem o mercado, abrangendo consumidores (clientes) e competidores, o mercado de capitais (acionistas e empresários de recursos financeiros), bem como a comunidade de maneira mais ampla. As associações de empregados (sindicatos e centrais sindicais), bem como os sindicatos patronais e confederações e associações de classes correspondentes, também devem ser colocadas entre os influenciadores externos.

Entretanto, o poder e a influência que esses influenciadores efetivamente exercerão, dependerá do país, do momento histórico e da configuração do sistema econômico. Bertero (in: FLEURY; FISCHER, 1996) avalia ser o Brasil um país cujo centro do poder empresarial ainda reside claramente na coalizão interna, na qual o proprietário ou o conjunto dos acionistas majoritários dispõe de hegemonia. Isto é, as relações entre os acionistas e os quadros administrativos, formados por profissionais, tendem a serem relações patrimoniais, e o poder dos quadros administrativos é mais de execução em esferas específicas.

Esse mesmo autor cita o sindicalismo organizado dos empregados como sendo um influenciador externo importante. No entanto, o poder dos sindicatos, enquanto influenciador externo tem sido pequeno se comparado a outros vetores do poder. Em sentido contrário, o governo também é apontado como grande influenciador externo, só que apoiando, coadjuvando e implementando objetivos de empresários. Outro influenciador externo potencialmente poderoso em certos momentos são os interesses aglutinados no mercado de capitais, particularmente o de acionistas.

\subsection{Formas organizacionais com base no poder}

Falcini $(1993$, p. 7) destaca as teorias de Etzioni, Blau e Scott e de Rhenman como sendo as mais conhecidas entre as que construíram sua tipologia organizacional com base no poder. Afirma o autor que "cada uma delas vê o foco do poder fixado nas características internas da organização, ou nas características externas ou em ambas". São elas:

Foco na estrutura interna: Na década de 50, Etzioni construiu sua tipologia organizacional exclusivamente com base nas características internas das organizações, classificando-as através dos meios de controle utilizados para se obter um comportamento desejado de seus participantes internos e um nível de envolvimento correspondente para com as mesmas. Nesse sentido, propôs três tipos básicos de organizações:

Coercitiva: os meios de controle são coercitivos e o envolvimento dos participantes internos é alienativo.

Utilitária: os meios de controle são remunerativos e o envolvimento daqueles participantes é calculativo.

Normativa: com meios de controle normativos e envolvimento moral dos participantes internos (FALCINI, 1993, p. 7).

Para Etzioni, estudioso das ideias de Max Weber, considerar a existência de organizações com dupla estrutura de obediência, abrangendo todas as organizações, permitiram a identificação de modelos alternativos de organização, tais como a mecânica e a orgânica.

Mecanicista: modelo que se ajusta às condições ambientais estáveis. Suas tarefas especializadas, precisas e hierarquias são bem definidas. Corresponde a organizações burocracia legal-racional de Weber. 
Orgânico: modelo adaptado às condições ambientais instáveis. Suas tarefas passam por mudanças constantes e sua natureza é cooperativa e interativa. Alto nível de comprometimento com as metas da organização.

Foco no meio ambiente: Blau e Scott centraram sua teoria nas características externas das organizações, decorrentes de seu meio ambiente, categorizando-as em função de seus beneficiários principais, ou seja, aqueles para cujo benefício são criadas as organizações. Propõem quatro tipos de organizações, que, na realidade, correspondem a quatro tipos de beneficiários:

Interesse de negócios: cujos beneficiários principais são os seus proprietários.

Serviços: onde os clientes são os beneficiários principais.

Benefício mútuo: que beneficia principalmente seus membros participantes.

Serviço público: beneficia o público em geral (FALCINI, 1993, p. 8).

Através dessa tipologia, deduz-se que a estrutura interna, sendo instrumentalizada apenas para gerar benefícios àqueles situados em seu meio ambiente externo, não possuiria o foco do poder (FALCINI, 1993).

Foco dividido: As características internas e externas à organização são ligadas por Rhenman, derivando daí quatro tipologias:

Marginais: correspondendo àquelas organizações sem qualquer foco estratégico interno, nem qualquer missão externa; suas mudanças estratégicas são oportunistas ou reativas.

Corporações: com foco estratégico interno, mas sem qualquer missão imposta de fora para dentro da organização.

Acessórias: operam exclusivamente em função de interesses específicos externos dos quais dependerão para sua própria sobrevivência.

Instituições: com foco estratégico interno e missão imposta de fora, que poderão ou não se corresponder (FALCINI, 1993, p. 8).

Nos primeiros três tipos, o poder interno é mais ou menos centralizado; já no quarto tipo, tem-se o poder dividido entre alianças internas e externas à organização.

Assim, todas essas teorias se limitam a explorar poucas dimensões do poder organizacional, o que vai inspirar Mintzberg no desenvolvimento de sua teoria (FALCINI, 1993).

\subsubsection{A Teoria de Mintzberg}

O enfoque desta teoria é demonstrar como os influenciadores externos e internos atuam nas respectivas coalizações, os meios e os sistemas de influência que utilizam os tipos de alianças internas e externas que se formam e os sistemas de metas resultantes, cujas combinações, feitas de várias maneiras, irão gerar as configurações do poder organizacional (FALCINI, 1993, p. 8).

Nessa perspectiva, Mintzberg (1983) distingue dois tipos de influenciadores que interferem na vida das organizações: os externos e os internos.

Os influenciadores internos são os empregados da organização que possuem voz ativa, ou seja, são as pessoas encarregadas de tomar decisão e executar ações em base regular ou permanente. Eles formam a coalizão interna. Quando o gestor da organização delega competência para outros indivíduos, manifesta-se o controle e, com ele, sistemas de influência que podem ser usados pelos vários participantes da coalizão interna.

Mintzberg (1983) reúne e sintetiza todos os elementos do poder que existem dentro e em torno das organizações, combinando de várias maneiras os influenciadores das coalizões interna e externa, os meios do sistema de influência que eles usam, os tipos de coalizões interna e externa 
que eles formam e os objetivos do sistema que resulta. A essas combinações resultantes é dado o nome de "configurações de poder". O autor identifica seis configurações de poder, e os considera como tipos puros, que parecem melhor caracterizar os estados mais comuns de equilíbrio de poder encontrados nas organizações. Essas configurações foram assim denominadas: instrumental, sistema fechado, autocracia, missionária, meritocracia e arena política (FALCINI, 1993, p. 11).

Instrumental: A organização serve a um influenciador externo dominador (ou a um grupo deles agindo em conjunto). Os empregados são induzidos a contribuir com os seus esforços, tendo pouca oportunidade para atuar nos jogos do poder. Esse tipo de configuração tende a emergir, quando a organização vivencia um poder externo, focalizado e organizado tipicamente em torno de uma dependência crítica ou de uma prerrogativa legal, que emana de um influenciador externo com objetivos claros e operacionais.

Sistema fechado: Neste caso, quem vai se servir da organização é a coalização interna burocrática, utilizando, para tal, os controles internos que são baseados em padrões burocráticos de trabalho. Os administradores-chave absorvem o poder, dirigindo a organização por meio de um sistema de metas e objetivos. As metas perseguidas, em ordem de importância, são as de sobrevivência, eficiência, controle e crescimento. Essa configuração tende a aparecer em organizações mais estabelecidas, tipicamente as grandes organizações que operam em ambientes simples e estáveis, com trabalhadores sem especialização e influenciadores externos dispersos.

Autocracia: A autocracia também enfrenta uma coalizão externa passiva. Todo o poder está focalizado no dirigente da organização, que a controla pessoalmente. Essa forma rígida de controle significa uma ausência virtual de jogos políticos; os empregados expressam uma lealdade ao dirigente ou deixam a organização. A autocracia persegue e, se necessário, maximiza qualquer objetivo que o dirigente deseje. As autocracias tendem a serem organizações pequenas e pouco visíveis; organizações novas ou antigas que sejam dirigidas por seus fundadores; organizações que operam em ambientes simples e dinâmicos, algumas vezes com líderes fortes ou enfrentando crises severas.

Missionária: A dominação, neste tipo, é efetuada através de uma ideologia, como forma de manter a coalizão externa passiva. A forte ideologia serve para amarrar a coalizão interna em torno dos seus objetivos ideológicos e permite, também, que os seus membros sejam confiáveis para tomar decisões, uma vez que todos eles compartilham as mesmas crenças e tradições. Dificilmente os jogos políticos se desenvolvem nessa configuração. Todos os esforços são devotados para perseguir o objetivo de preservar, expandir e/ou aperfeiçoar a missão da organização. A configuração missionária tende a emergir quando a organização vivenciou uma liderança carismática no passado e, talvez, uma história importante, passando a desenvolver fortes tradições em torno de uma missão clara, distinta e atrativa para os seus membros.

Meritocrática: O poder aqui é focado internamente, especificamente sobre seus profissionais especialistas. A presença de diferentes tipos de especialistas geralmente propicia boa dose de atividade política. Dessa forma, a coalizão externa pode ser mais bem descrita como passiva, embora ela pareça estar dividida. Devido ao seu treinamento, os especialistas possuem muitas oportunidades para a rotatividade e, por isso, a sua lealdade à organização é um fator fraco. A condição chave que faz surgir à meritocracia é a necessidade de a organização desempenhar um trabalho complexo, o qual requer alto nível de especialização na sua coalizão interna.

Arena política: A arena política é caracterizada por conflito, tanto na coalizão externa, que é dividida, quanto na coalizão interna, que é politizada. A arena política pode servir como estágio funcional e, na verdade, necessário na transição de uma configuração de poder para outra. Ela emerge quando uma organização vivencia um desafio à sua ordem de poder existente, 
ou aquela existente entre os seus influenciadores e, também, quando há forças equilibradas e irreconciliáveis dentro da organização.

Dessa forma, a premissa maior, que permeia essa teoria, é a de que existem várias razões para crer que o mundo das organizações tende a se auto-ordenar de modo natural, em grupos específicos com características comuns.

\subsection{Os conflitos}

Moreira e Cunha (2007) consideram que as ideias sobre conflito veiculadas pelas teorias iniciais, as chamadas de tradicionais, eram mais lineares; o conflito tinha de ser eliminado. Na década de 20, os autores clássicos e pioneiros da teoria organizacional, como Taylor, Weber e Fayol, enquadrados numa visão negativa sobre o conflito e os seus resultados, entendiam ser o conflito prejudicial para a eficiência organizacional. E além disso, devendo o mesmo ser reduzido à sua expressão mínima por meio de regulamentação apropriada e do controle total da hierarquia, de maneira que os trabalhadores dificilmente pudessem criar situações de tensão. Essa filosofia perdurou até as primeiras décadas do século XX.

No entanto, o pensamento sobre o conflito por parte dos cientistas sociais e, fundamentalmente, dos organizacionais, tem sofrido várias alterações. Robbins (1978) agrupou as diferentes visões em três categorias: tradicional, comportamental e interacionista.

Na opinião de Dreu (1997 in: MOREIRA; CUNHA, 2007, 155),

a evidência crescente sugere que o conflito pode ser benéfico para o desempenho nos grupos e organizações e o seu evitamento e supressão reduz a criatividade, a qualidade de decisão, o desenvolvimento de produtos e a comunicação entre os grupos. Portanto, estimular o conflito influencia o desempenho individual e organizacional. Muita ênfase nas conseqüências negativas pode desviar a atenção dos efeitos benéficos que pode ter (...).

No entendimento de Moreira e Cunha (2007) os efeitos das situações conflituais nos indivíduos manifestam-se na razão direta da sua relação, tanto com o posto de trabalho como com os diferentes elementos da organização e estendem-se à eficácia organizacional.

Morgan (1996, p. 36) define o conflito existente nas organizações como sendo;

pessoal, interpessoal ou entre grupos rivais e coalizações. O conflito pode ser construído dentro das estruturas organizacionais, nos papéis, nas atitudes e nos estereótipos, ou surgir em função de recursos escassos. Pode estar explícito ou implícito. Qualquer que seja a razão ou a forma que assuma a sua origem reside em algum tipo de divergência de interesses percebidos ou reais.

Motta (1998) afirma haver três grandes correntes na abordagem do conflito na organização. A primeira entende os conflitos como o resultado de disputa de interesses inconciliáveis inscritos na estrutura social e que invadem a organização. A segunda corrente percebe o conflito como algo envolvendo papéis em nível organizacional, resultantes da evolução tecnológica e econômica que imporia adaptações à organização da produção e, como conseqüência, uma crescente necessidade de controle dos gerentes sobre a coletividade de trabalhadores. Por fim, a terceira corrente trata o conflito como sendo essencialmente de personalidade e de percepções em nível individual, ou seja, uma discrepância entre aspirações individuais e imposições organizacionais.

Burrell e Morgan (1979, apud Hall, 1984) defendem três visões para conflito e poder. Na "visão unitária", o conflito poderia ser visto como um fenômeno raro e transitório que poderia ser eliminado através da ação gerencial apropriada. Seriam sempre conflitos interpessoais e cau- 
sados por funcionários problemáticos ou criadores de caso. Uma segunda visão, "a pluralista", encara o conflito como uma característica intrínseca e inerradicável dos assuntos organizacionais e enfatiza seus aspectos potencialmente positivos e funcionais. Uma terceira visão, denominada como "radical" pelos autores, encara o conflito como força motora onipresente e causadora de rupturas, que impele às mudanças na sociedade em geral e nas organizações em particular. Reconhecem que o conflito pode ser um aspecto reprimido do sistema social, nem sempre visível no nível empírico como realidade.

Para Lukes (1980), além dos conflitos abertos, observáveis, comportamentais, há os conflitos encobertos. Os conflitos encobertos são os ruídos que a direção não escuta. Assim, a não tomada de decisão (em relação à situação conflituosa) seria um meio pelo qual as demandas de mudanças nas atuais relações de poder seriam sufocadas antes mesmo de serem enunciadas, portanto mantidas encobertas ou eliminadas antes mesmo de ganharem acesso à arena de tomada de decisões. Lukes (1980) afirma, ainda, que haveria um terceiro tipo de conflito, o qual ele denomina de latente. Seriam conflitos que poderiam manifestar-se desde que determinados atores pudessem tomar consciência do quanto seus verdadeiros interesses são desconsiderados. Dessa forma pode haver relações de poder que não se expressam, necessariamente, em conflitos observáveis ou mesmo encobertos, na medida em que os interesses dos diferentes atores nem sempre seriam conscientemente articulados e observáveis.

De acordo com Mayer e Mariano (2009), os conflitos objetivos envolvem desacordo sobre eventos ou situações concretas, como o estabelecimento de metas, distribuição de tarefas, alocação de recursos, distribuição de recompensas, definição de políticas e procedimentos organizacionais, além de designação de funções e alocação de pessoas em cargos. Já os conflitos emocionais resultam de sentimentos de raiva, desconfiança, antipatia, medo e ressentimento, além de choque de personalidade e problemas de relacionamento.

Assim, os conflitos objetivos mais comuns nas organizações referem-se às tarefas, ao trabalho propriamente dito, já conflitos emocionais ou subjetivos referem-se aos conflitos que ocorrem a partir das interações e dos relacionamentos entre as pessoas.

No entendimento de Mayer e Mariano (2009), para que se instaure uma situação de conflito, é necessário que as partes reconheçam que seus interesses são divergentes. A oposição ou incompatibilidade e alguma forma de interação são outros fatores comuns nas definições de conflito, pois estabelecem as condições que determinam o ponto inicial do processo conflituoso. Esses autores apontam cinco estágios no processo de conflito, sendo eles (p. 275-277):

Estágio 1 - Oposição potencial ou incompatibilidade: para que um conflito se instaure, é necessário que existam condições que criem oportunidades para que ele surja.

Essas condições são:

Comunicação: a escolha das palavras, o tom e o gestual utilizados por uma pessoa para externar as suas idéias e pensamentos podem dar origem a conflitos.

Estrutura: os grupos dentro das organizações possuem metas e objetivos diferentes. Apesar de todos na empresa trabalharem para que os resultados sejam alcançados, há situações em que as áreas têm objetivos concorrentes.

Variáveis pessoais: diferentes tipos de personalidade atuando juntas podem dar origem a conflitos, especialmente nos casos em que indivíduos pouco maduros divergem e levam as suas divergências para o plano das disputas pessoais. Diferenças de sistema de valores como preconceitos, desacordos sobre a contribuição de alguém para o grupo e a recompensa merecida também são fonte de conflitos potenciais.

Estágio 2 - Cognição e personalização: é o estágio em que as questões do conflito cos- 
tumam ser definidas. As condições antecedentes só levam ao conflito se uma ou mais partes envolvidas forem afetadas e estiverem conscientes disso. Há o nível em que o conflito é percebido e o nível em que o conflito é sentido. Conflito percebido é a consciência de uma ou mais partes envolvidas, da existência das condições que geram oportunidades para o surgimento de conflitos. Conflito sentido é o envolvimento emocional em um conflito, gerando ansiedade, tensão, frustração ou hostilidade.

Estágio 3 - Definição de estratégias ou intenção: são as decisões de agir de uma determinada maneira durante um conflito. Cinco intenções ou estratégias de administração de conflitos: competir, colaborar, evitar, acomodar-se e conceder.

Competir: busca da satisfação dos próprios interesses, independentemente do impacto sobre a outra parte em conflito.

Colaborar: as partes em conflito buscam satisfazer os interesses de todos os envolvidos.

Evitar: uma das partes deseja fugir do conflito ou tenta desconsiderar a sua existência.

Acomodar-se: disposição de uma das partes em conflito de colocar os interesses do oponente antes dos seus próprios.

Conceder: situação na qual cada uma das partes de um conflito está disposta a abrir mão de algo para se chegar a uma solução para o conflito.

Estágio 4 - Comportamento: é neste estágio que os conflitos se tornam visíveis.

Estágio 5 - Consequência: Essas consequências podem ser funcionais ou disfuncionais. Consequências funcionais - os conflitos são construtivos quando melhoram a qualidade das decisões, estimulam a criatividade e a inovação, encorajam o interesse e a curiosidade dos membros do grupo, oferecem um meio para o arejamento dos problemas e a liberação das tensões e estimulam mudanças. Conseqüências disfuncionais - os conflitos podem reduzir a eficácia dos grupos, podem causar deficiências de comunicação, redução da coesão do grupo e subordinação de metas. Podem, assim, paralisar o grupo e ameaçar sua sobrevivência.

\subsection{Poder e conflito}

O poder e o conflito são processos que fazem parte das organizações. Para Aguillar (2008), a dinâmica da vida organizacional se desenvolve, principalmente, quando as conseqüências destes processos são as disputas internas entre áreas, departamentos, divisões e diretorias. Para esse autor, só os conflitos de poder dentro do contexto organizacional podem provocar estudos do comportamento dos indivíduos, que administram, gerenciam e operam os diferentes negócios da empresa. Nas organizações modernas, a natureza do poder está relacionada com a força dos profissionais mais atuantes, suas metas e objetivos, sua equipe e sua influência nas decisões estratégicas da organização.

De acordo com Moscovici (1997), três conjuntos interdependentes de variáveis internas influem no comportamento humano, sendo eles a competência, a energia e a ideologia. A competência compreende aspectos intelectuais inatos e adquiridos, conhecimentos, capacidades, experiência e maturidade. Uma pessoa competente executa ações adequadas e hábeis em seus afazeres, em sua área de atividade.

Uma tendência ao conflito está relacionada a atribuir conotação negativa, relacionando brigas, combates, destruição do grau de aprofundamento e intensidade. E a atribuição positivas, tais como o rompimento do equilíbrio da rotina, aguça a percepção e o raciocínio, assim como o estimular a criatividade.

Na opinião de Falk (2001), o conflito em si não é danoso nem patológico. É uma constante da dinâmica interpessoal, reveladora do nível energético. Suas conseqüências poderão ser 
positivas ou negativas, destrutivas, em decorrência do grau de aprofundamento e intensidade, da duração, do contexto, da oportunidade e do modo como ele é enfrentado e administrado.

Ainda para Falk (2001), o conflito possui numerosas funções positivas: rompe o equilíbrio da rotina, mobiliza energia latente do sistema, desafia acomodação de idéias e posições, desvenda problemas escondidos, aguça a percepção e o raciocínio, excita a imaginação e estimula a criatividade para soluções originais.

O quadro a seguir traz uma síntese dos efeitos positivos e negativos do conflito organizacional, sob o ponto de vista de Rahim.

\begin{tabular}{|c|c|}
\hline POSITIVOS & NEGATIVOS \\
\hline $\begin{array}{c}\text { Estimulo à inovação e à criatividade obtidas pelo } \\
\text { embate entre idéias divergentes }\end{array}$ & $\begin{array}{c}\text { Estresse individual e do grupo e insatisfação no } \\
\text { ambiente de trabalho. }\end{array}$ \\
\hline $\begin{array}{c}\text { Busca de soluções alternativas para os problemas } \\
\text { organizacionais }\end{array}$ & $\begin{array}{l}\text { Redução da comunicação entre indivíduos e gru- } \\
\text { pos }\end{array}$ \\
\hline Melhoria do desempenho individual e do grupo. & $\begin{array}{l}\text { Existência de um clima de desconfiança entre o } \\
\text { grupo, reduzindo a efetividade do trabalho. }\end{array}$ \\
\hline $\begin{array}{l}\text { Identificação de sinergia em soluções para proble- } \\
\text { mas comuns }\end{array}$ & Desgaste das relações interpessoais. \\
\hline $\begin{array}{c}\text { Indução dos indivíduos e grupos a encontrar novas } \\
\text { abordagens para os problemas. }\end{array}$ & Redução do desempenho individual e do grupo. \\
\hline \multirow[t]{2}{*}{$\begin{array}{l}\text { Indivíduos e grupos podem ser requeridos a articu- } \\
\text { lar e esclarecer suas posições e pontos de vistas. }\end{array}$} & $\begin{array}{c}\text { Torna os indivíduos e grupos mais resistentes às } \\
\text { mudanças. }\end{array}$ \\
\hline & $\begin{array}{c}\text { Redução do comprometimento e da lealdade na } \\
\text { organização. }\end{array}$ \\
\hline
\end{tabular}

Fonte: Adaptado de Rahim (2001 In: MAYER, MARIANO, 2009, p. 285).

\subsection{Exercício do poder nas organizações}

Fresch e Raven (1959 apud Spector, 2006) afirmam que a influência ou o poder que uma pessoa tem sobre outra, como um supervisor sobre um subordinado, é baseada em cinco fatores. Esses fatores envolvem características individuais e condições organizacionais referentes ao relacionamento entre líder e seguidor ou supervisor e subordinado. Apesar de que, essas bases do poder ser discutidas como sendo características dos supervisores, o poder surge da interação entre subordinado e supervisor. O supervisor faz uma tentativa de influenciar o subordinado, mas é o comportamento deste que determina se essa influência é eficaz ou não.

As cinco bases da influência e poder interpessoais, de French e Raven (1959 apud SPECTOR, 2006), e como elas podem ser usadas estão descritas no quadro a seguir.

\begin{tabular}{|c|c|}
\hline Bases & Utilização \\
\hline Experiência & Fornecer informações \\
\hline Referência & Fazer com que os subordinados gostem de você \\
\hline Legitimidade & Obter um alto cargo ou escalão \\
\hline Recompensa & Dar recompensas pela conformidade \\
\hline Coerção & Punir e não conformidade \\
\hline
\end{tabular}

Fonte: Spector (2006, p. 331).

Para Spector (2006), o poder da experiência é baseado no conhecimento e na perícia que o supervisor tem. Um subordinado, provavelmente, seguirá as diretrizes de uma pessoa que ele acredita ter conhecimento ou perícia especial sobre o assunto em questão. 
O poder de referência se dá na medida em que os subordinados gostam ou se identificam com o supervisor. Essa fonte de poder pode ser desenvolvida por meio de relacionamentos pessoais com outras pessoas a ser aumentada elevando-se o status do supervisor. Uma pessoa com status de celebridade, provavelmente, terá um alto poder de referência.

O poder legítimo é o poder inerente ao título de supervisor. Ele deriva da crença dos funcionários de que o supervisor tem o direito legítimo ou a autoridade para estar no comando. Grande parte da força desse poder é resultado dos valores do subordinado a respeito dos direitos do supervisor. Se o subordinado se recusa a reconhecer a autoridade de um supervisor, não haverá nenhum poder no título.

O poder de recompensa é a habilidade do supervisor de recompensar subordinados com bônus, atribuições desejadas, promoções ou aumentos de salário.

Já o poder coercitivo é a habilidade do supervisor de punir os subordinados com ações disciplinares, multas, demissão ou reduções de salário.

As organizações diferem à medida que os supervisores podem dar recompensas ou aplicar punições. Em empresas privadas, não é raro que um supervisor seja capaz de dar aumentos e promoções a um subordinado. Em organizações governamentais, um supervisor pode não ser capaz de fazer o mesmo, porque essas recomendações são determinadas por ações legislativas (SPECTOR, 2006).

Spector (2006) entende que quando utilizadas apropriadamente, as diversas formas de poder podem servir como ferramenta para melhorar o funcionamento das organizações. Elas também podem ser usadas para ajudar os indivíduos a terem sentimentos positivos sobre seu trabalho e ter um bom desempenho, porém existe um lado potencialmente negativo do poder. Alguns supervisores utilizam seu poder para maltratar seus subordinados, na crença de que medidas punitivas são necessárias para fazer com que as pessoas tenham um bom desempenho. Em outros casos, isso ocorre porque o supervisor gosta de exercer seu poder sobre os subordinados.

\subsection{Resolução de conflitos}

Para Lacerda (2009), negociar os conflitos é gerir a qualidade da comunicação entre os litigantes no sentido de conduzi-los à construção, por eles próprios, de suas soluções. Aprender a negociar, objetivamente, é acessar os meios que induzem à comunicação e à construção de relacionamentos que regulam as situações conflituosas e seu modo de acompanhamento na tomada de decisões. Para esse autor, as pessoas diferem e usam a negociação para lidar com suas diferenças, seja nas áreas interna e externa dos países, nas famílias, no trabalho e nas inúmeras formas de controvérsias. Embora a negociação ocorra todos os dias, não é fácil conduzi-la com segurança ao resultado pretendido. Negociar é conhecer o processo durante o qual duas ou mais partes, com um problema comum, mediante o emprego de técnicas diversas de comunicação, buscam obter um resultado ou solução que satisfaça de uma maneira razoável e justa seus objetivos, interesses, necessidades e aspirações.

Nessas condições, um negociador deve ter a capacidade de construir um processo de comunicação bilateral, vislumbrando uma decisão conjunta, entendendo e fazendo entender que há e sempre haverá diferentes ideias, interesses e necessidades no momento de uma negociação.

Lacerda (2009) alerta que quando um terceiro (instituição, sistemas legais, etc.) se faz presente entre o conflito das partes, esse assume para si a responsabilidade de criar alternativas, como se a negociação fosse uma realidade externa aos interesses das partes. Por isso, o negociador deve, objetivamente, iniciar o processo de negociação sempre com mais perguntas do que respostas. Ouvir mais do que falar, subentendendo-se, a partir daí, a impossibilidade de se iniciar uma negociação sem planejá-la. 
O conflito, na maioria dos casos, distancia o ser humano da racionalidade, direcionando-o para estados emocionais que comprometem a compreensão dos fatos. Em situações extremas, a maioria das pessoas ou se submetem às relações de poder, adotando comportamentos subservientes, ou se transformam em agressores, organizando-se em formas de enfrentamento, na tentativa de inverter as relações de dependência.

Fellipelli (2009) registra que fracasso de projetos importantes, briga de egos entre funcionários, queda de produtividade e desmotivação da equipe, além da perda de clientes, negócios e talentos são algumas das conseqüências enfrentadas por empresas que não prepararam os colaboradores para lidar com situações de conflito ou divergências que afetam o fluxo de trabalho.

Segundo pesquisa desenvolvida pela Fellipelli (2009), os brasileiros gastam em média 1,9 horas por semana na solução de conflitos, o equivalente a 91,2 horas por ano e 11,4 dias de trabalho. As empresas nacionais ficam atrás apenas das alemãs e irlandesas, ambas com perdas de 3,3 horas semanais, e das companhias norte-americanas (2,8 horas). Esse estudo foi realizado em nove países (Inglaterra, Bélgica, Brasil, Dinamarca, França, Alemanha, Irlanda, Holanda e Estados Unidos), com a participação de 5.000 executivos.

De acordo com a mesma pesquisa, $85 \%$ dos funcionários enfrentaram conflito em algum grau, e $29 \%$ fazem isso com freqüência. A principal causa dos desentendimentos dentro de uma organização brasileira é o estresse, fator apontado por $43 \%$ dos entrevistados. 0 choque de valores vem em segundo lugar, com $24 \%$ das reclamações. Já na média global, quase a metade dos funcionários (49\%) vê as diferenças de personalidades e luta de egos como os maiores geradores de conflitos, seguidos de estresse (34\%) e pressão por conta da elevada carga de trabalho (33\%). Dois terços dos funcionários entrevistados fizeram o possível para evitar um colega em razão de desentendimentos no trabalho, o que causa distrações e desconcentração da equipe. Um em cada sete (14\%) perdeu um dia de trabalho e $18 \%$ admitiram que já pediram demissão por conta de um conflito. No Brasil, 33\% dos entrevistados afirmam que evita ao máximo chegar a situações de atrito.

Fellipelli (2009) considera que para que o conflito seja positivo para as relações de trabalho e para a empresa, o treinamento é indispensável. A pesquisa apontou o Brasil como de maior índice de treinamentos no manejo de conflitos (60\%).

Para a solução ou estímulo de conflitos, a fim de mantê-los nos níveis desejados, Robbins sugere a utilização das seguintes técnicas de administração de conflitos (Mayer; Mariano, 2009, p. 281-282):

Resolução de problemas: encontros entre as partes conflitantes com o propósito de identificar o problema e resolvê-los por meio de discussão aberta.

Metas superordenadas: criação de uma meta compartilhada que não possa ser atingida sem a cooperação entre as partes conflitantes.

Expansão de recursos: quando o conflito é causado pela escassez de um recurso, a expansão do recurso pode criar uma solução ganho-ganho.

Não enfrentamento: suprimir o conflito ou evadir-se dele.

Suavização: minimizar as diferenças entre as partes conflitantes, enfatizando seus interesses comuns.

Concessão: cada uma das partes abre mão de algo valioso.

Comando autoritário: a administração usa sua autoridade formal para resolver o conflito e depois comunica seu desejo às partes envolvidas.

Alteração de variáveis humanas: utilização de técnicas de mudança comportamental, como treinamento em relações humanas, para alterar atitudes e comportamentos que causem conflitos.

Alteração de variáveis estruturais: mudanças na estrutura formal da organização e nos padrões de interações entre as partes conflitantes por meio de redesenho de atribuições, transferências, criação de posições coordenadas, etc. 


\section{CONSIDERAÇÕES FINAIS}

O artigo aborda o tema conflito de poder das organizações como fonte, propiciando uma reflexão, principalmente no que diz respeito às relações interpessoais no ambiente de trabalho.

Na literatura, encontram-se inúmeros estudos que buscam explicar as diversas nuances que envolvem o poder no ambiente das organizações, no entanto, nem todos são unânimes quanto aos fatores desencadeantes, nem quanto aos efeitos que os conflitos decorrentes do emprego desse poder refletem na organização.

De outra forma, referindo-se aos conflitos, a literatura aponta que os mesmos, na medida certa, podem ser considerados como benéficos à organização, uma vez que podem motivar o funcionário a um crescimento, tanto pessoal, quanto profissional, colaborando, dessa forma, para uma melhoria do desempenho individual e do grupo.

Quanto à resolução desses conflitos, a negociação é uma alternativa indicada, desde que o profissional designado para tal seja capacitado, isto é, que tenha conhecimento do processo desencadeador do conflito, para dessa forma, buscar uma solução que satisfaça de maneira razoável e justa os objetivos, interesses, necessidades e aspirações das partes envolvidas no conflito.

Assim, os conflitos ao mesmo tempo em que representam uma ameaça a estabilidade de uma organização, podem também representar uma via de crescimento conjunto, ou seja, organização, gestor e colaborador podem sair fortalecidos de uma situação conflitante, desde que usadas às alternativas corretas para a solução do mesmo.

\section{REFERENCIAS}

Aguillar, D. Poder e Conflito - Metáfora da Dominação. 2008. Disponível em: <http:// www.soartigos.com/articles/606/1/html>. Acesso em: 14 dez. 2012.

\section{BOWDITCH, J. L. Elementos do comportamento} organizacional. São Paulo: Pioneira, 1992.

DONATO, J.V.; KUBO, E. M.; DOMINGUES, C. R. Conflitos e obstáculos operacionais em gestão de projetos inovadores: um estudo empírico. Revista de Administração UFSM, v. 6, n. 4, p. 740-759, nov./dez. 2013.

FALCINI, P. Organizações como configurações naturais do poder. RAE - Revista de Administração de Empresas. São Paulo, v.33, n.1, p. 6-15, jan./fev. 1993. Disponível em: <http:// www16.fgv.br/rae/rae/index.cfm?FuseAction=Artigo $\& I D=721 \&$ Secao $=$ ARTIGOS\&Volu$\mathrm{me}=33 \&$ numero $=1 \& A n o=1993>$. Acesso em: 28 dez. 2012.

FALK, M.L.R. A competência gerencial nos conflitos interpessoais. REAd. 22. ed. v. 7, n. 4, jul./ago. 2001.

FELLIPELLI. Instrumentos de Diagnóstico e Desenvolvimento Organizacional. Pesquisa sobre Conflitos. Disponível em: <http://www. fellipelli.com.br/index_destaques_menu. asp?sub=27>. Acesso em: 02 dez. 2012.

FISCHER, R. M. O círculo do poder: as práticas invisíveis de sujeição nas organizações complexas. In: FLEURY, M. T. L.; FISCHER, R. M. (Coords.). Cultura e poder nas organizações. São Paulo: Atlas, 1989.

FOUCAULT, M. Microfísica do poder. Rio de Janeiro: Edições Graal, 1993.

GALBRAITH, J. K. Anatomia do poder. São Paulo: Pioneira, 1989.

Hall, R. H. Organizações: estrutura e processos. Rio de Janeiro: Prentice Hall do Brasil, 1984.

lacerda, S. I. Sem conflito não há negociação, sem negociação o resultado não pertence às partes. Disponível em: $<$ http://www.institutodenegociacao. 
com.br/index.php?option =com content\&view $=$ article\&id=87: sem-conflitonao-ha-negociacao-sem-negociacao-oresultado-nao-pertence-as-partes $\&$ catid $=14: a$ rtigos\&ltemid=95>. Acesso em: 03 dez. 2012.

LAKATOS, E.M; MARCONI, M.A. Fundamentos de metodologia científica. 5.ed. São Paulo: Atlas, 2003.

Lukes, S. Poder: uma visão radical. Brasília: Editora UnB, 1980.

MACÊDO, K.B. Cultura, poder e decisão na organização familiar brasileira. RAE-eletrônica. v.1, n. 1, jan./jun. 2002.

MAYER, V; MARIANO, S.R.H. O conflito nas organizações. 2009. Disponível em: <http:// www.scribal.com/aula12>. Acesso em: 30 nov. 2012.

MINTZBERG, H. Designing Effective Organizations. New Jersey: Prentice-Hall, 1983.

MIRANDA, S. O tabu do poder e da política nos estudos organizacionais. Revista de Administração UFSM, v. 2, n. 3, p. 490-501, mai./ago. 2009.

MOREIRA, R.B; CUNHA, P. Efeitos do conflito nas organizações: ameaça ou contributo para o desenvolvimento organizacional? 2007. Revista da Faculdade de Ciências Humanas e Sociais. n. 4. Edições Universidade Fernando Pessoa. Disponível em: http://hdl.handle. net/10284/443. Acesso em: 4 dez. 2012.

MORGAN, G. Imagens da organização. São Paulo: Atlas, 1996.

MOSCOVICl, F. Desenvolvimento interpessoal: treinamento em grupo. Rio de Janeiro: José Olympio, 1997.

Motta, P.R. Gestão contemporânea: a ciência e a arte de ser dirigente. 2.ed. Rio de Janeiro: Record, 1998.

PAGÈS, M. O poder das organizações: a dominação das multinacionais sobre os indivíduos. São Paulo: Atlas, 1987.

SILVA, G.V.; LACERDA, D. P. Relações de poder no projeto de economia de comunhão. Revista de Administração UFSM, v. 3, p. 76-93, jan./ abr. 2010.

SPECTOR, P.E. Psicologia nas organizações. Trad. Solange Aparecida Visconde. São Paulo: Saraiva, 2006.

ZALESNIK, A.; VRIES, M. F. R. O poder e a mente empresarial. São Paulo: Enio Atheus Guazzelli Cia, 1981. 